\title{
Hydrogen sulfide improves intestinal recovery following ischemia by endothelial nitric oxide-dependent mechanisms
}

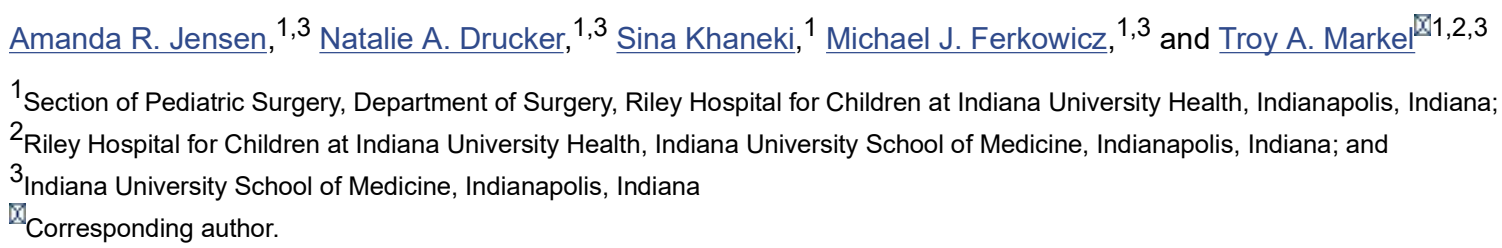

\section{Abstract}

Hydrogen sulfide $\left(\mathrm{H}_{2} \mathrm{~S}\right)$ is an endogenous gasotransmitter that has vasodilatory properties. It may be a novel therapy for intestinal ischemia-reperfusion (I/R) injury. We hypothesized that 1 ) $\mathrm{H}_{2} \mathrm{~S}$ would improve postischemic survival, mesenteric perfusion, mucosal injury, and inflammation compared with vehicle and 2) the benefits of $\mathrm{H}_{2} \mathrm{~S}$ would be mediated through endothelial nitric oxide. $\mathrm{C} 57 \mathrm{BL} / 6 \mathrm{~J}$ wild-type and endothelial nitric oxide synthase knockout (eNOS KO) mice were anesthetized, and a midline laparotomy was performed. Intestines were eviscerated, the small bowel mesenteric root identified, and baseline intestinal perfusion was determined using laser Doppler. Intestinal ischemia was established by temporarily occluding the superior mesenteric artery. Following ischemia, the clamp was removed, and the intestines were allowed to recover. Either sodium hydrosulfide ( $2 \mathrm{nmol} / \mathrm{kg}$ or $2 \mu \mathrm{mol} / \mathrm{kg} \mathrm{NaHS}$ ) in PBS vehicle or vehicle only was injected into the peritoneum. Animals were allowed to recover and were assessed for mesenteric perfusion, mucosal injury, and intestinal cytokines. $P$ values $<0.05$ were significant. $\mathrm{H}_{2} \mathrm{~S}$ improved mesenteric perfusion and mucosal injury scores following I/R injury. However, in the setting of eNOS ablation, there was no improvement in these parameters with $\mathrm{H}_{2} \mathrm{~S}$ therapy. Application of $\mathrm{H}_{2} \mathrm{~S}$ also resulted in lower levels of intestinal cytokine production following I/R. Intraperitoneal $\mathrm{H}_{2} \mathrm{~S}$ therapy can improve mesenteric perfusion, intestinal mucosal injury, and intestinal inflammation following $\mathrm{I} / \mathrm{R}$. The benefits of $\mathrm{H}_{2} \mathrm{~S}$ appear to be mediated through endothelial nitric oxide-dependent pathways.

NEW \& NOTEWORTHY $\mathrm{H}_{2} \mathrm{~S}$ is a gaseous mediator that acts as an anti-inflammatory agent contributing to gastrointestinal mucosal defense. It promotes vascular dilation, mucosal repair, and resolution of inflammation following intestinal ischemia and may be exploited as a novel therapeutic agent. It is unclear whether $\mathrm{H}_{2} \mathrm{~S}$ works through nitric oxide-dependent pathways in the intestine. We appreciate that $\mathrm{H}_{2} \mathrm{~S}$ was able to improve postischemic recovery of mesenteric perfusion, mucosal integrity, and inflammation. The beneficial effects of $\mathrm{H}_{2} \mathrm{~S}$ appear to be mediated through endothelial nitric oxide-dependent pathways.

Keywords: hydrogen sulfide, sodium hydrosulfide, intestinal ischemia, nitric oxide, endothelial nitric oxide synthase, perfusion, inflammation 
INTESTINAL ISCHEMIA continues to be a devastating intra-abdominal emergency with high morbidity and mortality attributable to the difficult and often late diagnosis. It accounts for over $2 \%$ of gastrointestinal illnesses and is often observed in the setting of abdominal aortic aneurysm surgery, small bowel transplantation, incarcerated hernias, intestinal volvulus, or following cardiopulmonary bypass $(\underline{14}, \underline{22}, \underline{26}$, 35). If the bowel can be revascularized, patients are often faced with secondary consequences of reperfusion injury, which can lead to metabolic acidosis, hemodynamic instability, sepsis, and multiple endorgan dysfunction (29). The mortality from intestinal ischemia can be as high as $65-74 \%(\underline{1}, \underline{28})$.

Present therapies for intestinal ischemia are designed to treat the sequelae of the problem. There are no medical treatments available that can effectively lessen or potentially reverse the devastating aftermath of intestinal ischemia. Therefore, a novel therapeutic treatment is essential to aid in improving outcomes in this patient population. In this regard, the use of hydrogen sulfide $\left(\mathrm{H}_{2} \mathrm{~S}\right)$ has recently been identified as a potential therapeutic strategy for gastrointestinal disease. $\mathrm{H}_{2} \mathrm{~S}$ donors have been found to be cytoprotective in the setting of NSAID-induced intestinal injury through modulation of the bile and the microbiome $(4, \underline{5})$. Additionally, in the setting of colitis, endogenous $\mathrm{H}_{2} \mathrm{~S}$ production increases and is found to decrease following resolution of colitis, and exogenous application also causes significant reduction in the severity of colitis $(\underline{33})$.

$\mathrm{H}_{2} \mathrm{~S}$ has also been found to be of benefit in intestinal ischemia-reperfusion (I/R) injury. Preconditioning with an $\mathrm{H}_{2} \mathrm{~S}$ donor before intestinal ischemia has been found to prevent mitochondrial dysfunction by a $\mathrm{BK}_{\mathrm{Ca}}$ channel-dependent mechanism (23). In the postischemic period, application of an $\mathrm{H}_{2} \mathrm{~S}$ donor decreases apoptosis and preserves intestinal architecture (15). Other I/R-related injuries including myocardial infarction, cerebral ischemia, and transplant-associated renal ischemia were also observed to receive therapeutic benefit and end-organ protection with use of $\mathrm{H}_{2} \mathrm{~S}$ donors $(\underline{7}, \underline{13}, \underline{21}, \underline{24})$. $\mathrm{H}_{2} \mathrm{~S}$ likely plays an important role physiologically through cellular signaling and vasodilation. Additionally, it exhibits anti-inflammatory, antioxidant, and antiapoptotic effects $(\underline{15}, \underline{23}, \underline{36})$. All of these studies support the notion that the protective properties of $\mathrm{H}_{2} \mathrm{~S}$ may be exploited in drug therapy for inflammatory pathology and specifically in the setting of ischemic injury.

$\mathrm{H}_{2} \mathrm{~S}$ may work through endothelial nitric oxide synthase (eNOS) to bring about its protective effects. $\mathrm{H}_{2} \mathrm{~S}$ can donate a sulfur moiety to a cysteine on eNOS, which then promotes its dimerization (2). Only once dimerized can eNOS facilitate the production of $\mathrm{NO}(\underline{11})$. NO, as a downstream effector, may then promote vascular dilation (30). Other studies on coronary artery physiology have suggested that $\mathrm{H}_{2} \mathrm{~S}$ may exert its effects through both NO-dependent and NO-independent pathways, depending on native vascular tonicity (32). Testai et al. (32) specifically demonstrated that in normotensive rats, $\mathrm{H}_{2} \mathrm{~S}$ worked through NOdependent pathways, but in hypertensive rats, $\mathrm{H}_{2} \mathrm{~S}$ mediated its effects through NO-independent pathways.

Presently, there is no clear understanding of how $\mathrm{H}_{2} \mathrm{~S}$ mediates its protective effects in the intestinal mesenteric vascular bed. Therefore, before $\mathrm{H}_{2} \mathrm{~S}$ therapy is used in a clinical setting, the downstream pathways of this novel treatment must be further elucidated. We hypothesized that 1) $\mathrm{H}_{2} \mathrm{~S}$ would improve postischemic survival, mesenteric perfusion, intestinal mucosal injury scores, and intestinal inflammation more effectively compared with vehicle following intestinal I/R and 2) the benefits of $\mathrm{H}_{2} \mathrm{~S}$ therapy would be mediated through eNOS-dependent pathways.

\section{MATERIALS AND METHODS}

Murine intestinal I/R model. Experimental protocols and animal use were approved by the Indiana University Institutional Animal Care and Use Committee. Wild-type (WT) adult male mice (C57BL/6J, stock no: 00664, 8-12 wk, 20-30 g; Jackson, Bar Harbor, ME) and eNOS KO mice (B6.129P2Nos3tm1Unc/J, stock no: 002684, 8-12 wk, 20-30 g; Jackson) underwent at least $48 \mathrm{~h}$ of acclimation to the 
new environment before experimentation. Mice were provided normal chow and water and kept in 12h:12-h light-dark cycle housing.

Mice were anesthetized using 3\% isofluorane, followed by maintenance at $1.5 \%$ isofluorane in oxygen. A heating pad was used to achieve temperature homeostasis, and the abdomen was prepped using a hair removal lotion followed by sterile preparation with $70 \%$ ethanol and betadine. To account for intraoperative fluid losses, $1 \mathrm{ml}$ of $0.9 \%$ normal saline was injected subcutaneously preoperatively. All animals were given analgesia ( $1 \mathrm{mg} / \mathrm{kg}$ buprenorphine and $5 \mathrm{mg} / \mathrm{kg}$ carprofen) by subcutaneous injection preoperatively.

Under sterile conditions, a midline laparotomy was performed, and the intestines were eviscerated. The base of the superior mesenteric artery was identified and clamped using an atraumatic microvascular clamp. The intestines were then placed back into the abdominal cavity, and the abdomen was temporarily closed using silk suture to prevent evaporative losses. Following $60 \mathrm{~min}$ of intestinal ischemia, the abdomen was reopened, and the atraumatic clamp was removed. The abdominal fascia and skin were then closed in a two-layer fashion with silk suture. Before complete abdominal closure, the animals underwent intraperitoneal injection with $250 \mu 1$ of PBS (vehicle control) or $250 \mu 1$ of sodium hydrosulfide (NaHS) at doses of $2 \mathrm{nmol} / \mathrm{kg}\left(1.12 \times 10^{-4} \mathrm{mg} / \mathrm{kg}\right)$ or $2 \mu \mathrm{mol} / \mathrm{kg}\left(1.12 \times 10^{-1} \mathrm{mg} / \mathrm{kg}\right)$ in PBS. Triple antibiotic ointment was applied to the abdominal incision following complete closure. Following surgery, animals were placed in a cage on a heating pad and allowed to awaken. Once fully recovered, animals were returned to animal housing.

Perfusion analysis. Animals were assigned to the perfusion protocol ( $n=10$ per vehicle group, 8 per each NaHS-treated group) as follows: 1) WT IR + vehicle, 2) WT IR + $2 \mathrm{nmol} / \mathrm{kg} \mathrm{NaHS}, 3$ ) WT IR $+2 \mu \mathrm{mol} / \mathrm{kg}$ NaHS, 4) eNOS KO IR + vehicle, 5) eNOS KO IR + $2 \mathrm{nmol} / \mathrm{kg}$ NaHS, and 6 ) eNOS KO IR + $2 \mu \mathrm{mol} / \mathrm{kg}$ NaHS. Perfusion was analyzed using a laser-Doppler perfusion imager (LDI; Moor Instruments, Wilmington, DE). Images were acquired at baseline, at the initial clamping of the superior mesenteric artery, and $24 \mathrm{~h}$ after recovery. A region of interest was created around the entirety of exposed intestines to obtain a flux mean perfusion within this region. Three images were acquired at each time point and averaged. Perfusion data were expressed as a percentage of baseline (means $\pm \mathrm{SE}$ ). After the 24-h recovery analysis, animals were euthanized with isofluorane overdose and cervical dislocation, and intestinal tissues were explanted for further analyses.

Histological injury score. Intestinal tissues were harvested following euthanasia of experimental groups. Terminal ileums were then fixed using $4 \%$ paraformaldehyde with subsequent dehydration in $70 \%$ ethanol. Intestines were paraffin embedded, sectioned, and subsequently stained with hematoxylin and eosin. A histological scoring method of intestinal damage was used as previously described: 0 , no damage; 1 , subepithelial space at the villous tip; 2, loss of mucosal lining at the villous tip; 3, loss of less than half of the villous structure; 4 , loss of more than half of the villous structure; and 5, transmural necrosis $(\underline{8}, \underline{34})$. All histological sections were evaluated by two blinded authors (A. Jensen, N. Drucker), and scores were averaged.

Intestinal cytokine analysis. Following euthanasia, mouse intestinal tissues designated for protein analysis were harvested, snap frozen in liquid nitrogen, and stored at $-80^{\circ} \mathrm{C}$. Once ready to use, intestines were thawed and homogenized in RIPA buffer (Sigma, St. Louis, MO) with phosphatase and protease inhibitors (1:100 dilution, Sigma) using a Bullet Blender tissue homogenizer (Next Advance, Averill Park, NY). Following homogenization, samples were centrifuged at 12,000 revolution/min to pellet extraneous tissue, and supernatants were collected and placed into fresh Eppendorf tubes. Total protein concentration was quantified with the Bradford assay using a spectrophotometer (VersaMax microplate reader; Molecular Devices, Sunnyvale, CA).

Murine intestinal levels of interleukin 6 (IL-6), IL-9, IL-10, C-X-C ligand 10 (IP10), macrophage 
inflammatory protein 2 (MIP-2), granulocyte-colony stimulating factor (G-CSF), MIP-1 $\alpha$, eotaxin, vascular endothelial growth factor (VEGF), fibroblast growth factor 2 (FGF-2), hepatocyte growth factor (HGF), and C-X-C ligand 1 (KC) were quantified using a Bio-Plex 200 multiplex beaded assay system (Bio-Rad, Hercules, CA) with customizable multiplex plates for murine inflammatory cytokines (Millipore, Billerica, MA). Assays were performed at 1:20 dilution according to the manufacturer's instructions and are reported in nanograms of cytokine per gram of total intestinal protein (means $\pm \mathrm{SE}$ ).

Statistical analysis. All statistical analysis was performed using GraphPad Prism 7 (GraphPad Software, La Jolla, CA). Perfusion, histology, and cytokine analysis were reported as means $\pm \mathrm{SE}$ and compared using the Mann-Whitney $U$-test for nonparametric variables. $P$ values $<0.05$ were considered statistically significant.

\section{RESULTS}

NaHS improves intestinal perfusion following I/R injury through eNOS-dependent pathways. Intestinal perfusion was compared in treatment groups at $24 \mathrm{~h}$ following I/R injury (Fig. 1). Low- and highdose NaHS treatment promoted significantly improved postischemic perfusion levels $(78.3 \pm 7.3 \%, 63.4 \pm$ $7.2 \%)$ compared with vehicle $(26.4 \pm 5.3 \% ; P=0.0002, P=0.003$, respectively) in WT animals assessed at $24 \mathrm{~h}$ following injury. Conversely, in eNOS KO mice, perfusion was similar among treated and untreated groups, and no significant differences were found between vehicle $(34.4 \pm 6.6 \%), 2 \mathrm{nmol} / \mathrm{kg} \mathrm{NaHS}(32.1 \pm$ $6.9 \%)$, or $2 \mu \mathrm{mol} / \mathrm{kg} \mathrm{NaHS}(52.7 \pm 9.2 \%)$ groups $(P=0.72$ and $P=0.33$, respectively).

NaHS prevents mucosal injury following I/R through eNOS-dependent pathways. Significant sloughing of intestinal mucosa and destruction of the epithelial layer in the crypt-villous architecture was seen in PBS vehicle-treated WT groups (3.20 \pm 0.30$)$ compared with WT mice treated with $2 \mathrm{nmol} / \mathrm{kg}$ NaHS $(1.30 \pm 0.25, P<0.0001)$ or $2 \mu \mathrm{mol} / \mathrm{kg}$ NaHS $(1.60 \pm 0.29, P=0.002)$. No significant improvements were seen in histological injury with NaHS therapy in eNOS KO animals (Fig. 2).

NaHS attenuates the intestinal inflammatory cytokine response following I/R injury. Intestinal cytokines and growth factors were affected by $\mathrm{H}_{2} \mathrm{~S}$ therapy following ischemic injury. IL-6 was noted to be significantly decreased in WT intestines exposed to both $2 \mathrm{nmol} / \mathrm{kg}$ and $2 \mu \mathrm{mol} / \mathrm{kg} \mathrm{NaHS}$, whereas IL-9, IL-10, VEGF, and FGF-2 were only lowered by the $2 \mu \mathrm{mol} / \mathrm{kg}$ dose of NaHS (Fig. 3). In murine animals with eNOS KO, although decreases in IL-9, IL-10, and VEGF were observed, they did not reach statistical significance. IL-6 and FGF-2 were the only two cytokines to have significant decreases in chemokine production. IL-6 significantly decreased with $2 \mu \mathrm{mol} / \mathrm{kg}$ NaHS treatment, and FGF-2 significantly decreased with $2 \mathrm{nmol} / \mathrm{kg}$ NaHS treatment. HGF was not affected in this model system by NaHS or with eNOS ablation.

Inflammatory chemokines in the intestinal segments were also affected by NaHS following injury (Fig. 4). MIP-1 $\alpha$, eotaxin, and IP-10 were significantly decreased only in the $2 \mu \mathrm{mol} / \mathrm{kg}$-treated groups, whereas there was no effect on these factors with the lower doses of NaHS in WT intestinal segments. Levels of MIP-2, G-CSF, and KC were significantly decreased in intestines with both tested doses of NaHS. Lastly, in evaluation of cytokines from NaHS-treated intestines from eNOS KO animals, there were no significant differences compared with the vehicle-treated group.

\section{DISCUSSION}

Intestinal ischemia is a devastating abdominal emergency. Many times necrotic intestine needs to be surgically excised, which can leave patients with an inadequate amount of bowel to promote normal nutrient absorption. Present therapies are inadequate at protecting ischemic intestine, and, therefore, novel therapies are being explored. Herein we observed that $\mathrm{H}_{2} \mathrm{~S}$ treatment (in the form of NaHS) following I/R 
injury can provide gastrointestinal protection. These beneficial properties appear to be mediated, in part, by eNOS.

We observed improvements in mesenteric perfusion and preservation of intestinal mucosal integrity and decreased inflammation following ischemic insult. However, although we did observe significant benefits with NaHS therapy following intestinal ischemia, these beneficial properties were not observed in the absence of eNOS. Similarly, Coletta et al. (9) previously reported that $\mathrm{H}_{2} \mathrm{~S}$-induced angiogenesis requires NO biosynthesis and inhibition of eNOS abolished the $\mathrm{H}_{2} \mathrm{~S}$-stimulated angiogenic response. Their research suggested that $\mathrm{NO}$ and $\mathrm{H}_{2} \mathrm{~S}$ worked synergistically to increase cGMP production, cGMP-dependent protein kinase $\mathrm{G}$ activation, and angiogenesis. Additionally, in their studies, the vasorelaxant action of $\mathrm{H}_{2} \mathrm{~S}$ also required the presence of endogenously produced $\mathrm{NO}$, further confirming the significant complexity of biological interactions between these two gasotransmitters.

In this study, we observed equivalent rates of improvement in mesenteric perfusion with the addition of both low and high doses of NaHS. These improvements in perfusion were lost when eNOS was genetically ablated. Intestinal mucosal injury was also improved with NaHS therapy. Although it is possible that $\mathrm{H}_{2} \mathrm{~S}$ can directly preserve intestinal mucosal integrity by limiting inflammation and apoptosis $(\underline{15}, \underline{23}, \underline{36})$, it is also equally likely that the main effects of $\mathrm{H}_{2} \mathrm{~S}$ therapy are to promote vasodilation ( $\left.\underline{3}\right)$ and improve mesenteric blood flow. Better intestinal reperfusion after injury in itself will limit further mucosal damage and intestinal inflammation. Furthermore, if the effects of $\mathrm{H}_{2} \mathrm{~S}$ were solely on the intestinal epithelium, then knocking out eNOS should not have had an effect on host preservation.

Significant elevations in intestinal chemokines, including MIP, eotaxin, and chemokine ligand 10 (IP-10) have been noted following intestinal ischemia and are thought to be responsible for leukocyte mobilization to the areas of injured bowel $(17, \underline{31})$. These cells are responsible for injury repair but also promote inflammation, which may be detrimental to the host. For example, lymphocyte influx is thought to be detrimental to recovery, as lymphocyte-depleted animals had better outcomes following intestinal ischemia (6). However, other leukocyte classes may actually promote intestinal recovery by digesting dead cells and repairing the extracellular matrix (27). Additionally, markers of neovascularization have been elevated after intestinal ischemia $(10, \underline{16})$. Neovasculogenesis increases intestinal capillary density to restore oxygen balance and nutrient homeostasis to injured bowel.

In a similar fashion, we also appreciated a significant decrease in intestinal chemokines. High-dose NaHS $(2 \mu \mathrm{mol} / \mathrm{kg})$ decreased MIP-1 $\alpha$, eotaxin, and IP-10 levels, whereas both low- and high-range doses significantly decreased intestinal MIP-2, G-CSF, and KC levels. Although we observed lower levels of several chemokines in eNOS KO animals following NaHS therapy, none of these reached statistical significance. Therefore, $\mathrm{H}_{2} \mathrm{~S}$-mediated decreases in all assessed chemokines following intestinal ischemia appeared to be dependent on the presence of eNOS.

We also observed a significant decrease in several inflammatory cytokines and growth factors after NaHS therapy. IL-6, IL-9, IL-10, VEGF, and FGF-2 were all decreased after NaHS therapy although only IL-6 was noted to be decreased at both the $2 \mathrm{nmol} / \mathrm{kg}$ and $2 \mu \mathrm{mol} / \mathrm{kg}$ concentrations. HGF was not impacted by NaHS therapy. Although decreases in IL-9, IL-10, and VEGF appeared to be dependent on functioning eNOS, production of IL-6 appeared to also decrease in the mid-range dose for eNOS KO animals, and FGF-2 appeared to decrease in the low-range NaHS-treated eNOS KO animals. HGF was also not affected by ablation of eNOS. These findings would indicate that many of the inflammatory factors tested, but certainly not all of them, were impacted by the presence of functional eNOS. On the basis of the data presented herein, we surmise that the presence of eNOS promotes $\mathrm{H}_{2} \mathrm{~S}$-mediated improvements in vascular tonicity. Because of better mesenteric perfusion, injured intestines are able to recover more effectively, and inflammatory cytokines and chemokines are not as abundant. 
The superior mesenteric artery ligation model of intestinal $\mathrm{I} / \mathrm{R}$ does not model clinical intestinal ischemia to its fullest. Although complete small bowel ischemia is possible secondary to superior mesenteric artery thrombus or embolus, the majority of intestinal ischemic episodes are due to segmental intestinal ischemia, such as may be seen with adhesive bowel obstructions or incarcerated hernias. Nonetheless, this model mimics the most severe form of intestinal ischemia and, therefore, is likely considered the best animal model available to test the effectiveness of novel therapies.

Conclusion. In conclusion, $\mathrm{H}_{2} \mathrm{~S}$ appears to be a novel therapeutic agent for the treatment of intestinal I/R injury. The beneficial effects of improved mesenteric perfusion, histological injury, and inflammatory cytokine and chemokine modulation appear to be mediated through eNOS. Additional modes of delivery, including inhaled delivery systems, need to be tested with this model to determine the best clinical application. These factors, as well as the effects of $\mathrm{H}_{2} \mathrm{~S}$ on long-term survival and neurodevelopment, need to be assessed before widespread clinical implementation.

\section{GRANTS}

This work was supported by grant KL2TR001106 (A. Shekhar, PI) from the National Institutes of Health, National Center for Advancing Translational Sciences, Clinical and Translational Sciences Award; and Indiana University Health, Indianapolis, IN.

\section{DISCLOSURES}

No conflicts of interest, financial or otherwise, are declared by the authors.

\section{AUTHOR CONTRIBUTIONS}

A.R.J., S.K., and M.J.F. performed experiments; A.R.J., N.A.D., S.K., M.J.F., and T.A.M. analyzed data; A.R.J., N.A.D., S.K., M.J.F., and T.A.M. interpreted results of experiments; A.R.J. prepared figures; A.R.J. drafted manuscript; A.R.J., N.A.D., S.K., M.J.F., and T.A.M. edited and revised manuscript; A.R.J., N.A.D., S.K., M.J.F., and T.A.M. approved final version of manuscript; T.A.M. conceived and designed research.

\section{REFERENCES}

1. Acosta-Merida MA, Marchena-Gomez J, Hemmersbach-Miller M, Roque-Castellano C, HernandezRomero JM. Identification of risk factors for perioperative mortality in acute mesenteric ischemia. World J Surg 30: 1579-1585, 2006. doi:10.1007/s00268-005-0560-5. [PubMed: 16865320] [CrossRef: $10.1007 / \mathrm{s} 00268-005-0560-5]$

2. Altaany Z, Ju Y, Yang G, Wang R. The coordination of S-sulfhydration, S-nitrosylation, and phosphorylation of endothelial nitric oxide synthase by hydrogen sulfide. Sci Signal 7: ra87, 2014. doi:10.1126/scisignal.2005478. [PubMed: 25205851] [CrossRef: 10.1126/scisignal.2005478]

3. Bełtowski J, Jamroz-Wiśniewska A. Hydrogen sulfide and endothelium-dependent vasorelaxation. Molecules 19: 21183-21199, 2014. doi:10.3390/molecules 191221183. [PubMed: 25521118] [CrossRef: 10.3390/molecules 191221183]

4. Blackler RW, De Palma G, Manko A, Da Silva GJ, Flannigan KL, Bercik P, Surette MG, Buret AG, Wallace JL. Deciphering the pathogenesis of NSAID enteropathy using proton pump inhibitors and a hydrogen sulfide-releasing NSAID. Am J Physiol Gastrointest Liver Physiol 308: G994-G1003, 2015. doi:10.1152/ajpgi.00066.2015. [PubMed: 25882612] [CrossRef: 10.1152/ajpgi.00066.2015]

5. Blackler RW, Motta JP, Manko A, Workentine M, Bercik P, Surette MG, Wallace JL. Hydrogen sulphide 
protects against NSAID-enteropathy through modulation of bile and the microbiota. Br J Pharmacol 172: 992-1004, 2015. doi:10.1111/bph.12961. [PMCID: PMC4314190] [PubMed: 25297699] [CrossRef: $10.1111 / \mathrm{bph} .12961]$

6. Chen J, Crispín JC, Tedder TF, Dalle Lucca J, Tsokos GC. B cells contribute to ischemia/reperfusionmediated tissue injury. J Autoimmun 32: 195-200, 2009. doi:10.1016/j.jaut.2009.02.021.

[PMCID: PMC3734555] [PubMed: 19342197] [CrossRef: 10.1016/j.jaut.2009.02.021]

7. Chin KY, Qin C, May L, Ritchie RH, Woodman OL. New pharmacological approaches to the prevention of myocardial ischemia-reperfusion injury. Curr Drug Targets. 2015 Oct 1. [Epub ahead of print.] 10.2174/1389450116666151001112020. [PubMed: 26424394] [CrossRef: $10.2174 / 1389450116666151001112020]$

8. Chiu CJ, McArdle AH, Brown R, Scott HJ, Gurd FN. Intestinal mucosal lesion in low-flow states. I. A morphological, hemodynamic, and metabolic reappraisal. Arch Surg 101: 478-483, 1970. doi:10.1001/archsurg.1970.01340280030009. [PubMed: 5457245] [CrossRef: 10.1001/archsurg.1970.01340280030009]

9. Coletta C, Papapetropoulos A, Erdelyi K, Olah G, Módis K, Panopoulos P, Asimakopoulou A, Gerö D, Sharina I, Martin E, Szabo C. Hydrogen sulfide and nitric oxide are mutually dependent in the regulation of angiogenesis and endothelium-dependent vasorelaxation. Proc Natl Acad Sci USA 109: 9161-9166, 2012. doi:10.1073/pnas.1202916109. [PMCID: PMC3384190] [PubMed: 22570497] [CrossRef: 10.1073/pnas.1202916109]

10. El-Assal ON, Paddock H, Marquez A, Besner GE. Heparin-binding epidermal growth factor-like growth factor gene disruption is associated with delayed intestinal restitution, impaired angiogenesis, and poor survival after intestinal ischemia in mice. J Pediatr Surg 43: 1182-1190, 2008. doi:10.1016/j.jpedsurg.2008.02.053. [PMCID: PMC2495084] [PubMed: 18558204] [CrossRef: 10.1016/j.jpedsurg.2008.02.053]

11. Forstermann U, Sessa WC. Nitric oxide synthases: regulation and function. Eur Heart J 33: 829-837, 2012. doi:10.1093/eurheartj/ehr304. [PMCID: PMC3345541] [PubMed: 21890489] [CrossRef: 10.1093/eurheartj/ehr304]

13. Gheibi S, Aboutaleb N, Khaksari M, Kalalian-Moghaddam H, Vakili A, Asadi Y, Mehrjerdi FZ, Gheibi A. Hydrogen sulfide protects the brain against ischemic reperfusion injury in a transient model of focal cerebral ischemia. J Mol Neurosci 54: 264-270, 2014. doi:10.1007/s12031-014-0284-9.

[PubMed: 24643521] [CrossRef: 10.1007/s12031-014-0284-9]

14. Gonzalez LM, Moeser AJ, Blikslager AT. Animal models of ischemia-reperfusion-induced intestinal injury: progress and promise for translational research. Am J Physiol Gastrointest Liver Physiol 308: G63G75, 2015. doi:10.1152/ajpgi.00112.2013. [PMCID: PMC4297854] [PubMed: 25414098] [CrossRef: 10.1152/ajpgi.00112.2013]

15. Henderson PW, Weinstein AL, Sohn AM, Jimenez N, Krijgh DD, Spector JA. Hydrogen sulfide attenuates intestinal ischemia-reperfusion injury when delivered in the post-ischemic period. J

Gastroenterol Hepatol 25: 1642-1647, 2010. doi:10.1111/j.1440-1746.2010.06380.x. [PubMed: 20880173] [CrossRef: 10.1111/j.1440-1746.2010.06380.x]

16. Ishii M, Tanaka E, Imaizumi T, Sugio Y, Sekka T, Tanaka M, Yasuda M, Fukuyama N, Shinozaki Y, Hyodo K, Tanioka K, Mochizuki R, Kawai T, Mori H, Makuuchi H. Local VEGF administration enhances healing of colonic anastomoses in a rabbit model. Eur Surg Res 42: 249-257, 2009.

doi:10.1159/000210671. [PubMed: 19346745] [CrossRef: 10.1159/000210671] 
17. Jawa RS, Quist E, Boyer CW, Shostrom VK, Mercer DW. Mesenteric ischemia-reperfusion injury upregulates certain $\mathrm{CC}, \mathrm{CXC}$, and $\mathrm{XC}$ chemokines and results in multi-organ injury in a time-dependent manner. Eur Cytokine Netw 24: 148-156, 2013. doi:10.1684/ecn.2014.0345. [PubMed: 24589386] [CrossRef: 10.1684/ecn.2014.0345]

21. Karwi QG, Whiteman M, Wood ME, Torregrossa R, Baxter GF. Pharmacological postconditioning against myocardial infarction with a slow-releasing hydrogen sulfide donor, GYY4137. Pharmacol Res 111: 442-451, 2016. doi:10.1016/j.phrs.2016.06.028. [PubMed: 27378570] [CrossRef: 10.1016/j.phrs.2016.06.028]

22. Lauz Medeiros SH, de Oliveira Menezes A, Zogbi L, Frasson de Souza Montero E. N-acetylcysteine use in hepatic ischemia/reperfusion in rats minimizing bowel injury. Transplant Proc 48: 2371-2374, 2016. doi:10.1016/j.transproceed.2016.06.003. [PubMed: 27742300] [CrossRef: 10.1016/j.transproceed.2016.06.003]

23. Liu Y, Kalogeris T, Wang M, Zuidema MY, Wang Q, Dai H, Davis MJ, Hill MA, Korthuis RJ. Hydrogen sulfide preconditioning or neutrophil depletion attenuates ischemia-reperfusion-induced mitochondrial dysfunction in rat small intestine. Am J Physiol Gastrointest Liver Physiol 302: G44-G54, 2012. doi:10.1152/ajpgi.00413.2010. [PMCID: PMC3345957] [PubMed: 21921289] [CrossRef: 10.1152/ajpgi.00413.2010]

24. Lobb I, Jiang J, Lian D, Liu W, Haig A, Saha MN, Torregrossa R, Wood ME, Whiteman M, Sener A. Hydrogen sulfide protects renal grafts against prolonged cold ischemia-reperfusion injury via specific mitochondrial actions. Am J Transplant 17: 341-352, 2017. doi:10.1111/ajt.14080. [PubMed: 27743487] [CrossRef: 10.1111/ajt.14080]

26. Mazzei MA, Mazzei FG, Marrelli D, Imbriaco G, Guerrini S, Vindigni C, Civitelli S, Roviello F, Grassi R, Volterrani L. Computed tomographic evaluation of mesentery: diagnostic value in acute mesenteric ischemia. J Comput Assist Tomogr 36: 1-7, 2012. doi:10.1097/RCT.0b013e31823b4465. [PubMed: 22261763] [CrossRef: 10.1097/RCT.0b013e31823b4465]

27. McCracken JM, Allen LA. Regulation of human neutrophil apoptosis and lifespan in health and disease. J Cell Death 7: 15-23, 2014. doi:10.4137/JCD.S11038. [PMCID: PMC4167320] [PubMed: 25278783] [CrossRef: 10.4137/JCD.S11038]

28. Nonthasoot B, Tullavardhana T, Sirichindakul B, Suphapol J, Nivatvongs S. Acute mesenteric ischemia: still high mortality rate in the era of 24-hour availability of angiography. J Med Assoc Thai 88, Suppl 4: S46-S50, 2005. [PubMed: 16623001]

29. Oldenburg WA, Lau LL, Rodenberg TJ, Edmonds HJ, Burger CD. Acute mesenteric ischemia: a clinical review. Arch Intern Med 164: 1054-1062, 2004. doi:10.1001/archinte.164.10.1054.

[PubMed: 15159262] [CrossRef: 10.1001/archinte.164.10.1054]

30. Rapoport RM, Draznin MB, Murad F. Endothelium-dependent relaxation in rat aorta may be mediated through cyclic GMP-dependent protein phosphorylation. Nature 306: 174-176, 1983. doi:10.1038/306174a0. [PubMed: 6316142] [CrossRef: 10.1038/306174a0]

31. Santen S, Wang Y, Laschke MW, Menger MD, Jeppsson B, Thorlacius H. Rho-kinase signalling regulates CXC chemokine formation and leukocyte recruitment in colonic ischemia-reperfusion. Int J Colorectal Dis 25: 1063-1070, 2010. doi:10.1007/s00384-010-0997-3. [PubMed: 20593289] [CrossRef: 10.1007/s00384-010-0997-3]

32. Testai L, D'Antongiovanni V, Piano I, Martelli A, Citi V, Duranti E, Virdis A, Blandizzi C, Gargini C, Breschi MC, Calderone V. Different patterns of H2S/NO activity and cross-talk in the control of the 
coronary vascular bed under normotensive or hypertensive conditions. Nitric Oxide 47: 25-33, 2015. doi:10.1016/j.niox.2015.03.003. [PubMed: 25795591] [CrossRef: 10.1016/j.niox.2015.03.003]

33. Wallace JL, Vong L, McKnight W, Dicay M, Martin GR. Endogenous and exogenous hydrogen sulfide promotes resolution of colitis in rats. Gastroenterology 137: 569-578, 2009.

doi:10.1053/j.gastro.2009.04.012. [PubMed: 19375422] [CrossRef: 10.1053/j.gastro.2009.04.012]

34. Watkins DJ, Yang J, Matthews MA, Besner GE. Synergistic effects of HB-EGF and mesenchymal stem cells in a murine model of intestinal ischemia/reperfusion injury. J Pediatr Surg 48: 1323-1329, 2013. doi:10.1016/j.jpedsurg.2013.03.032. [PMCID: PMC3710437] [PubMed: 23845626] [CrossRef: 10.1016/j.jpedsurg.2013.03.032]

35. Yeung KK, Groeneveld M, Lu JJ, van Diemen P, Jongkind V, Wisselink W. Organ protection during aortic cross-clamping. Best Pract Res Clin Anaesthesiol 30: 305-315, 2016.

doi:10.1016/j.bpa.2016.07.005. [PubMed: 27650341] [CrossRef: 10.1016/j.bpa.2016.07.005]

36. Zuidema MY, Peyton KJ, Fay WP, Durante W, Korthuis RJ. Antecedent hydrogen sulfide elicits an antiinflammatory phenotype in postischemic murine small intestine: role of heme oxygenase-1. Am J Physiol Heart Circ Physiol 301: H888-H894, 2011. doi:10.1152/ajpheart.00432.2010. [PMCID: PMC3191101] [PubMed: 21666111] [CrossRef: 10.1152/ajpheart.00432.2010]

Figures and Tables 
Fig. 1.

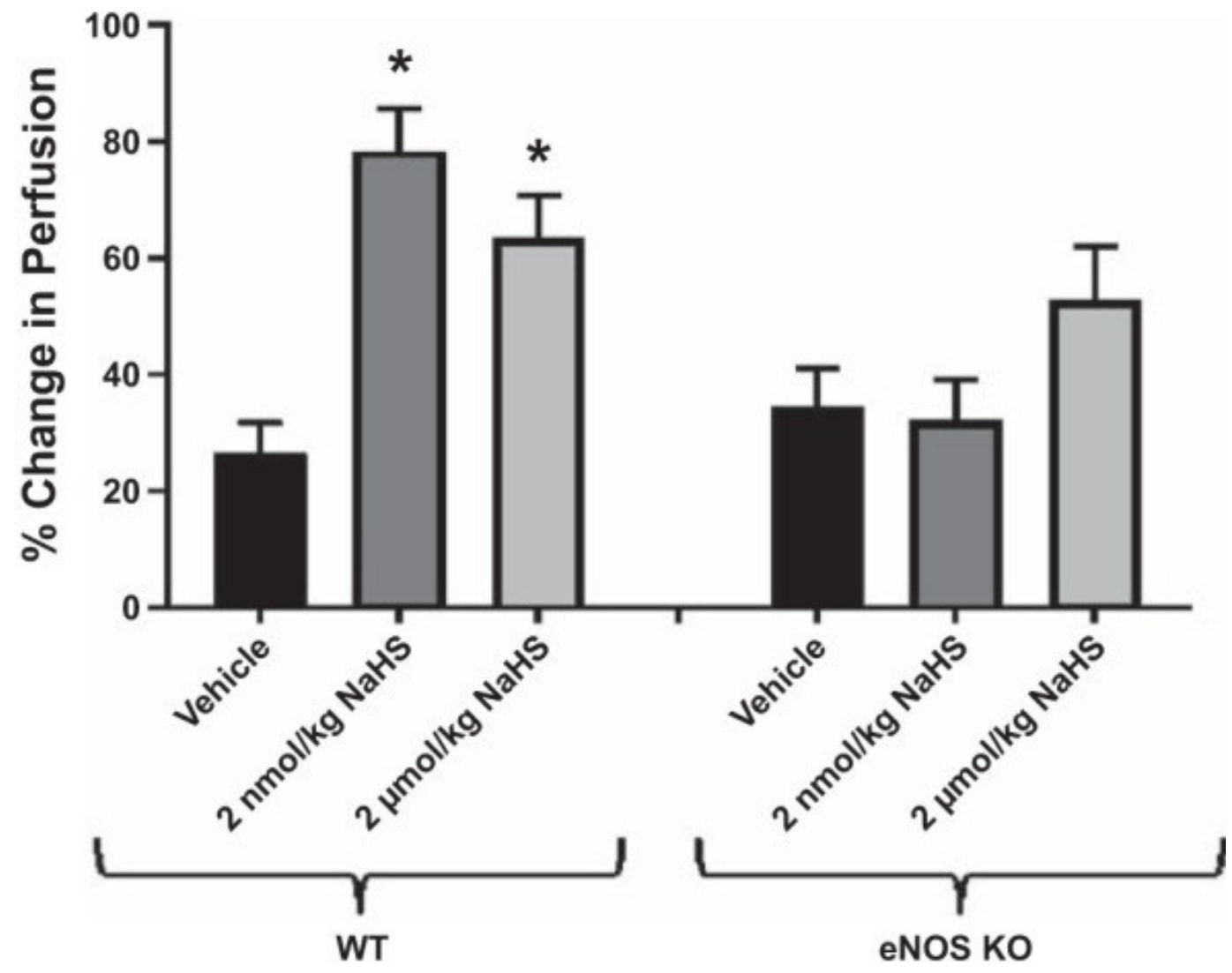

Hydrogen sulfide $\left(\mathrm{H}_{2} \mathrm{~S}\right)$ improves mesenteric perfusion following ischemic injury through endothelial nitric oxide synthase (eNOS)-dependent pathways. Postischemic mesenteric perfusion was significantly increased with both low- and highrange doses of sodium hydrosulfide (NaHS) in wild-type (WT) animals. However, there were no observed improvements in postischemic mesenteric perfusion following treatment in eNOS knockout $(\mathrm{KO})$ animals $\left({ }^{*} P<0.05\right.$ vs. respective vehicle). 
Fig. 2.

A

Wildtype

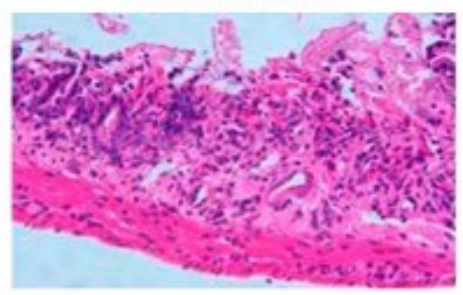

eNOS KO

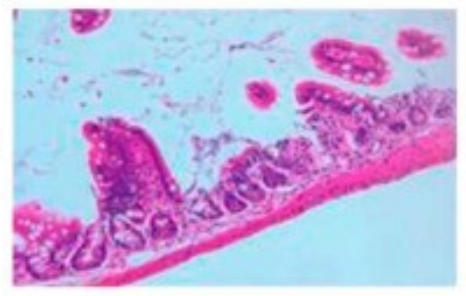

$2 \mathrm{nmol} / \mathrm{kg} \mathrm{NaHS}$
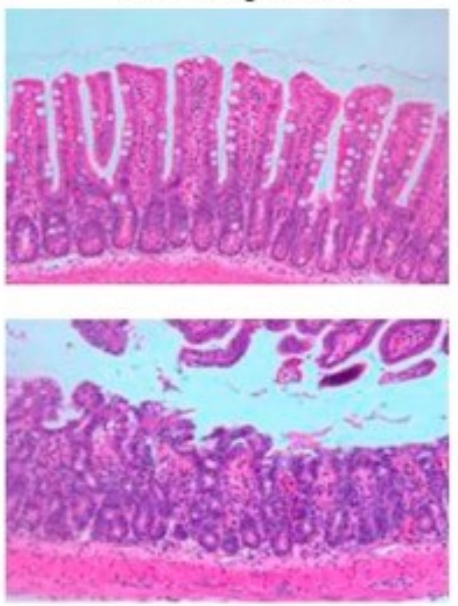

$2 \mu \mathrm{mol} / \mathrm{kg} \mathrm{NaHS}$
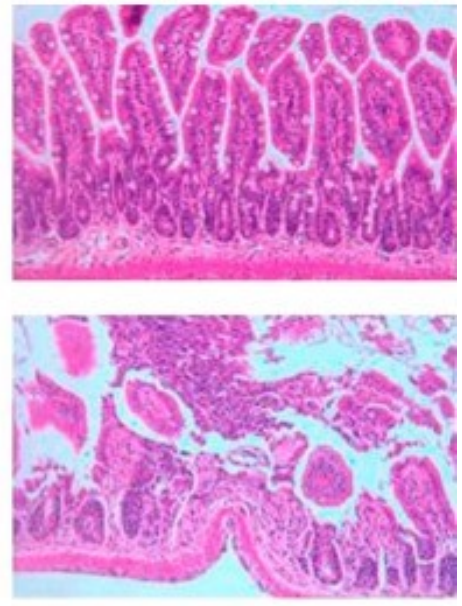

B

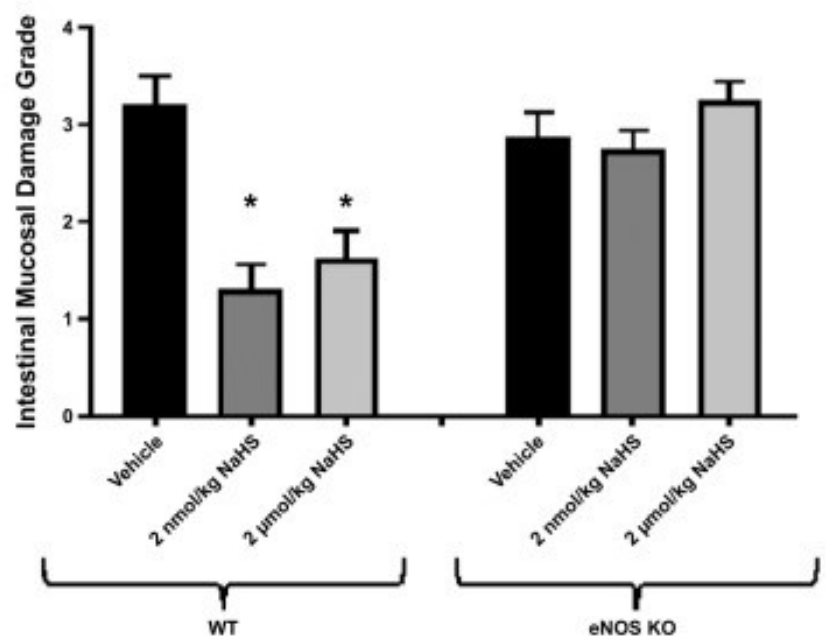

Histological examination of small intestine following intestinal ischemia and reperfusion (I/R). $A$ : representative histology slides of each treatment group (hematoxylin and eosin stain, $\times 20$ ) demonstrating improvements in intestinal histology with NaHS therapy in WT animals but not in eNOS KO animals. $B$ : histological scoring of intestinal specimens $\left({ }^{*} P<0.05\right.$ vs. respective vehicle). 
Fig. 3.
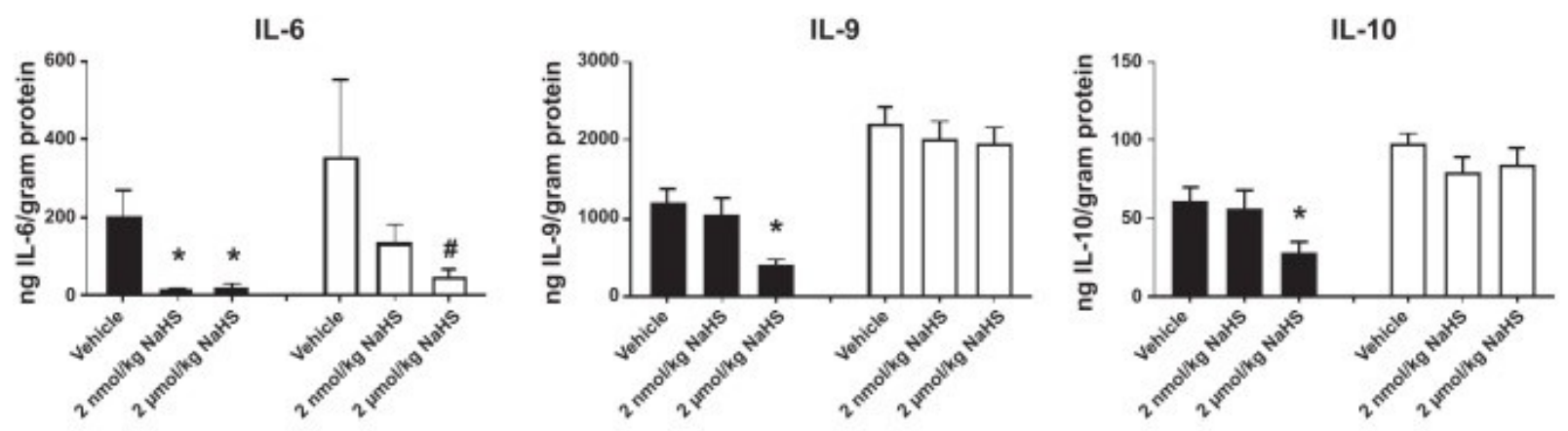

VEGF

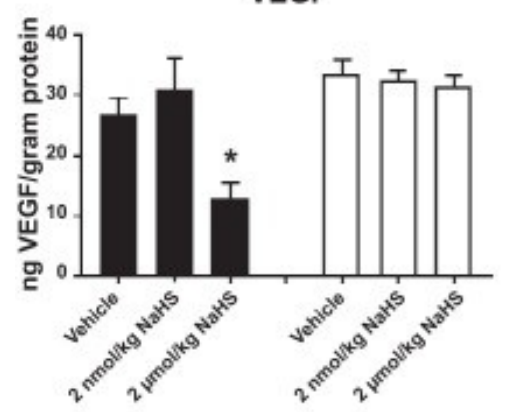

FGF-2
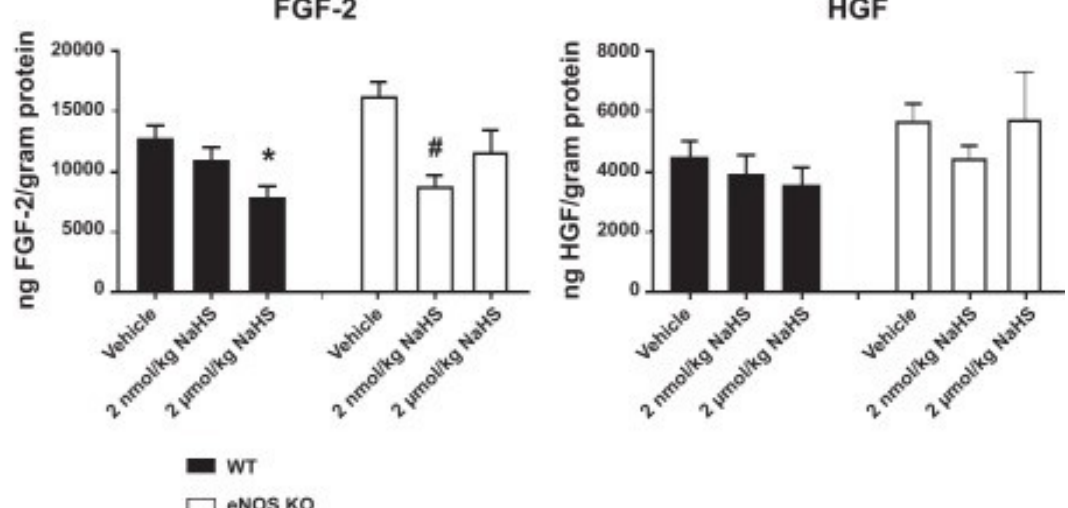

Inflammatory cytokines and growth factors are impacted by $\mathrm{H}_{2} \mathrm{~S}$ therapy following intestinal I/R. Intestinal levels of IL-6, IL-9, IL-10, VEGF, and fibroblast growth factor 2 (FGF-2) are decreased with $\mathrm{H}_{2} \mathrm{~S}$ therapy following intestinal ischemia. $\mathrm{H}_{2} \mathrm{~S}$ decreases in IL-9, IL-10, and VEGF appear to be facilitated by intact eNOS, whereas decreases in IL-6 and FGF-2 may work through $\mathrm{H}_{2} \mathrm{~S}$-independent pathways. Hepatocyte growth factor (HGF) does not appear to be affected by $\mathrm{H}_{2} \mathrm{~S}$ therapy or ablation of eNOS $(* P<0.05$ vs. WT vehicle, $\# P<0.05$ vs. eNOS KO vehicle). 
Fig. 4.
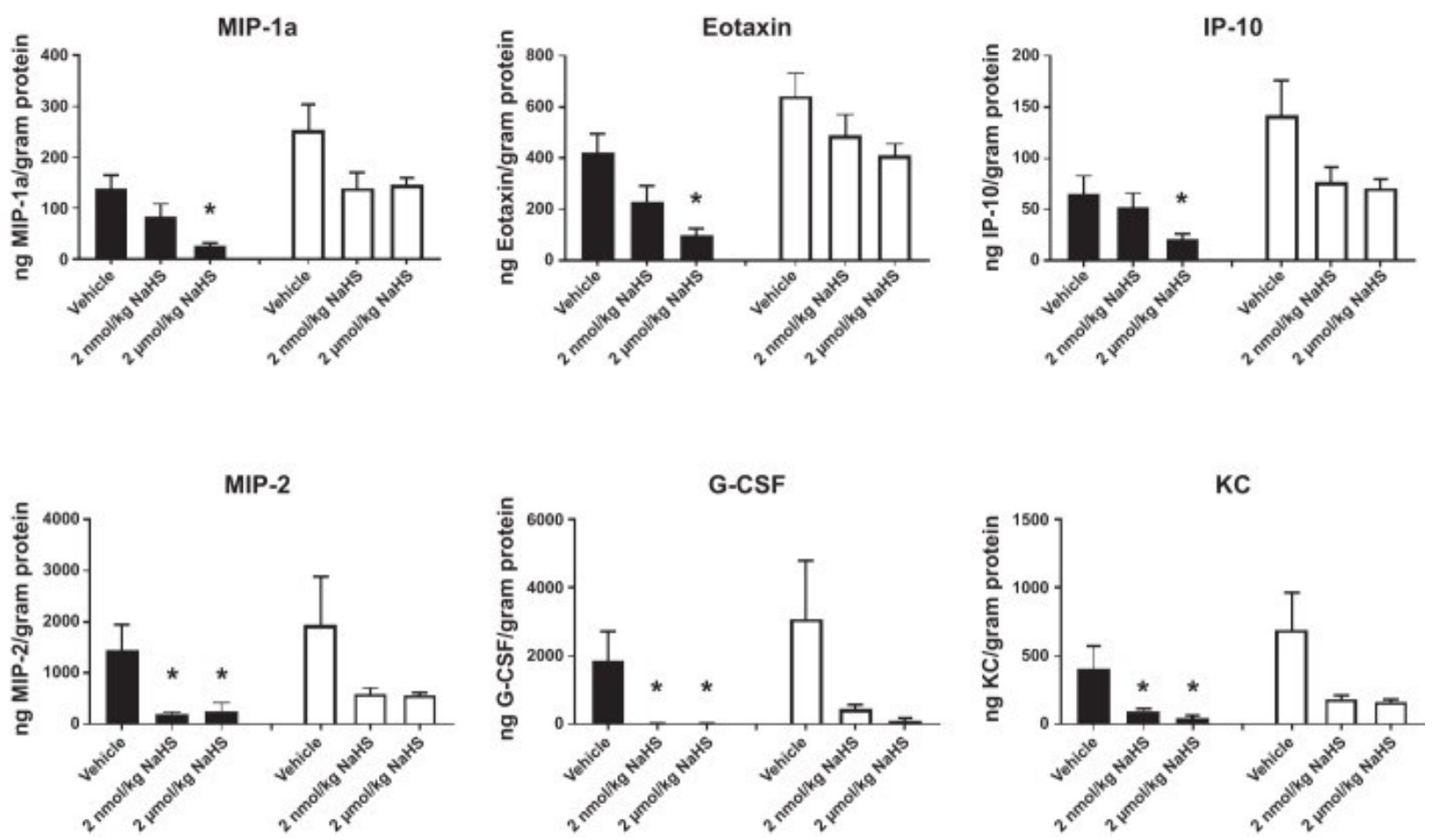

Chemokines are impacted by $\mathrm{H}_{2} \mathrm{~S}$ therapy following intestinal I/R. Intestinal levels of macrophage inflammatory protein $1 \alpha$ (MIP-1 $\alpha$ ), eotaxin, chemokine ligand 10 (IP-10), MIP-2, granulocyte-colony stimulating factor (G-CSF), and C-X-C ligand $1(\mathrm{KC})$ are decreased in ischemic intestines following $\mathrm{H}_{2} \mathrm{~S}$ therapy. Levels of these factors were not impacted significantly by genetic ablation of $\operatorname{NOS}(* P<0.05$ vs. WT vehicle).

Articles from American Journal of Physiology - Gastrointestinal and Liver Physiology are provided here courtesy of American Physiological Society 